\title{
INSECTICIDAL EFFICACY OF MINTWEED, YAM BEAN AND CELERY SEED EXTRACTS ON Aedes aegypti L.
}

\section{YONGKHAMCHA B. AND INDRAPICHATE K. *}

School of Biology, Institute of Science, Suranaree University of Technology, Nakhon Ratchasima 30000, Thailand.

*Corresponding Author: Email- korakod@sut.ac.th

Received: March 08, 2012; Accepted: April 03, 2012

\begin{abstract}
Biological control of Aedes aegypti, the dengue virus vector, is needed to replace synthetic insecticides. This study demonstrated the insecticidal efficacy of water and ethanolic seed extracts of mintweed Hyptis suaveolens (MSE), yam bean Pachyrhizus erosus (YSE) and celery Apium graveolens (CSE) on controlling of Ae. aegypti larvae and adults. The cytotoxicity of the extracts was investigated by brine shrimp lethality assay (BSLA). Yam bean extracts were highly cytotoxic to brine shrimps. All seed ethanolic extracts were more toxic to mosquitoes than water extracts. The insecticidal efficacy of all extracts ranged as YSE/e $>$ YSE/w $>$ MSE/e $>$ CSE/e $>$ MSE/w $>$ CSE/w. YSE/e was most toxic to Ae. aegypti $2^{\text {nd }}$ instar larvae and adults with LC50 of $16.22 \pm 0.20 \mu \mathrm{g} / \mathrm{ml}$ and $91.41 \pm 0.49 \mu \mathrm{g} / \mathrm{ml}$ respectively and much higher than MSE/s and CSE/e. YSE in combinations produced strong synergistic effects to the other extracts. The insecticidal activities of MSE and CSE were mild. They could lessen the activity of YSE. This study demonstrates that the safe utilization of plant seed extracts, particularly of the very toxic yam bean seeds, as Ae. aegypti biological control agents are possible by either individuals or suitable combinations with other plant or seed extracts.
\end{abstract}

Key words- insecticidal efficacy, mintweed, yam bean, celery, Aedes aegypti.

Citation: Yongkhamcha B. and Indrapichate K. (2012) Insecticidal Efficacy of Mintweed, Yam Bean and Celery Seed Extracts on Aedes aegypti L. International Journal of Agriculture Sciences, ISSN: 0975-3710 \& E-ISSN: 0975-9107, Volume 4, Issue 3, pp-207-212.

Copyright: Copyright@2012 Yongkhamcha B. and Indrapichate K. This is an open-access article distributed under the terms of the Creative Commons Attribution License, which permits unrestricted use, distribution, and reproduction in any medium, provided the original author and source are credited.

\section{Introduction}

Aedes aegypti $\mathrm{L}$. is the major vector of dengue virus, flavivirus, which transmits dengue hemorrhagic fever (DHF), the deathful disease in the tropical and subtropical regions. The outbreak of DHF appears to be cyclic and repeats every 2-3 years. In Thailand, DHF continues to be one of the major public concerns since its incidence had greatly increased from 46,829 to 115,845 cases during 2006-2010. Particularly in 2010, the incident rate of DHF was 182.36 per 100,000 and the mortality rate was 0.22 per 100,000 or $0.12 \%$ [1]. The re-emergence of DHF is primarily related to the Ae. aegypti reproduction. To avoid mosquito bites, mosquito nets are traditionally used, while physical catch and kill or uses of some plant products are also common. Plant products, such as pyrethrins, carvacrol, quassia, nicotine, allicin, anabasine, azadirachtin, d-limonene, and triptolide, are widely used in mosquito eradiation before the introduction of synthetically organic insecticides of pyrethroids and organophosphates [2]. However, the synthetic insecticides cause mosquito resistant and adverse effects to non-target organisms and environment [3-4]. Therefore, natural products from plants and bacteria have been researched to reduce the mosquito population and sustain the environment. Bacillus thuringiensis which produces crystal endotoxin has been introduced in the control of insect pests, including mosquitoes [5]. New phytochemicals as alternatives for controlling Ae. aegypti have been searched [6-8].

A few studies on insecticidal effects of plant seed products in controlling Ae. aegypti. Mintweed Hyptis suaveolens (L.) Poit is an aromatic weed possesses some medicinal properties and traditionally used to treat gastrointestinal infection, cramps and pain as well as to treat skin infections [9-10]. Mintweed seeds contained insecticidal activity [11-14]. Yam bean Pachyrhizus erosus L. is a tuber-root climbing plant. Its seeds possess a potent antitumor activity [15-16] and high toxic property to insects, fishes, rats, and fungi $[3,17]$. Celery Apium graveolens $L$. is an aromatic and spicy vegetable. Its seeds provide a remedy for urinary tract infections and degeneration of joints [18]. Celery seeds were able to repel 
insects, including larvae, and adult mosquitoes [19]. This study aimed to explore insecticidal efficacy of the seed extracts of mintweed, yam bean and celery for controlling the second instar larvae and the adults of Ae. aegypti.

\section{Materials and Methods \\ Seed Collection and Extract Preparation}

Mintweed seeds were collected on Suranaree University of Technology campus. Yam bean and celery seeds were purchased from local farms in Mahasarakham and Nakhon Ratchasima, Thailand. Mintweed seeds were soaked in water and removed their mucilage before extraction. All seeds were cleaned, air dried and ground to powder. Ten grams of the seed powder were extracted in $150 \mathrm{ml}$ of water or $70 \%$ ethanol in Soxhlet extractor (Buchi model B811, Germany). The extracts were evaporated, dried and stored at $-20^{\circ} \mathrm{C}$ until used. Dimethylsulfoxide (DMSO) and pyrethroid were purchased from Sigma Chemical Co. (St. Louis, MO, USA).

\section{Mosquito Rearing}

Ae. aegypti was a gift from the Communicable Disease Control Centre, Zone 6, Ministry of Public Health, Khon Kaen, Thailand, and reared in the Center for Scientific and Technological Equipment, Suranaree University of Technology by the standard rearing techniques of World Health Organization (WHO). The eggs on a filter paper were placed on a pottery bowl containing water which was in a steel-net wire-cage $(50 \times 50 \times 50 \mathrm{~cm})$ and allowed to hatch at $26{ }^{\circ} \mathrm{C}$ and $75 \%$ relative humidity. The larvae were transferred into enamel trays $(30 \times 21 \times 5 \mathrm{~cm})$ and fed with ground rat food. The adults were maintained in a cage $(80 \times 80 \times 80 \mathrm{~cm})$. The males were fed with syrup containing vitamins and the females were fed with guinea pig blood.

\section{Brine Shrimp Lethality Assay (BSLA)}

Brine shrimp (Artemia salina L.) eggs were purchased from a local fish shop. They were hatched and reared in artificial seawater (120 g/l sea salt) under continuous light, at $25^{\circ} \mathrm{C}$ for $24 \mathrm{~h}$ [20]. Ten nauplii were transferred into a 24-well plate containing $200 \mathrm{ml}$ of artificial seawater. The seed extracts of various concentrations were added and cultured for $12 \mathrm{~h}$. DMSO, $(0.1 \% \mathrm{v} / \mathrm{v})$ and $1 \mu \mathrm{g} / \mathrm{ml}$ pyrethroid were used as controls. The numbers of dead (non-motile) nauplii were counted and calculated for mortality. The median lethal concentration (LC50) was analyzed by Probit analysis.

\section{Larval Mortality Test}

The extract powder was dissolved in water or $0.1 \%$ DMSO. Fifty larvae, $2^{\text {nd }}$ instar, were gently transferred into $10 \mathrm{ml}$ of water in a$20 \mathrm{ml}$ vial and treated with $0-100 \mathrm{mg} / \mathrm{ml}$ extracts for $24 \mathrm{~h}$. Individual or combination $(1: 1, v / v)$ of the extracts were tested. DMSO and pyrethroid were used as controls. The tests were performed in triplicate and two repeats. The dead larvae were counted, calculated for mortality and analyzed for LC50 values.

\section{Adult Mortality Test}

Fifty mosquitoes, newly emerged, were transferred into a steel wire-net cage and the cage was covered with a plastic sheet. Five milliliters of extract solutions of different concentrations were firstly sprayed into the cage containing the mosquitoes. After 12 $\mathrm{h}, 5 \mathrm{ml}$ of the extracts were secondly resprayed. The dead mosquitoes were counted after $12 \mathrm{~h}$ of the second spray. Individual and combination (pair wise; 1:1, v/v) of the extracts were applied. DMSO and pyrethroid were used as controls. The tests were performed in triplicate and two repeats. The mortality was calculated and analyzed for LC50 values. The percentage of mortality was corrected by Abbott's formula as following:

$\%$ Test mortality - \% control mortality x 100

$\%$ Mortality $=\frac{100-\% \text { control mortality }}{100}$

\section{Data Analysis}

All data were analyzed by analysis of variance (ANOVA) and completely randomized design (CRD) using Statistical Package for the Social Sciences (SPSS) program for Windows, v.17. The means were compared using the Duncan's Multiple Range Test (DMRT). The mortality was corrected by Abbott's formula [21]. The median lethal concentration, LC50, was determined by Probit analysis [22].

\section{Results \\ Cytotoxicity}

Cytotoxicity of the seed extracts of mintweed (MSE), yam bean (YSE), and celery (CSE) was investigated by brine shrimp lethality assay (BSLA). The toxicity of all extracts were concentration dependent, although the toxic magnitudes were broadly different due to the plant seeds and the extract solvents. The ethanolic extracts of all seeds showed much higher toxic than the water extracts (Table 1). The median lethal concentration, LC50 at $24 \mathrm{~h}$, of the ethanolic extracts ranged as YSE/e > CSE/e > MSE/e and of the water extracts ranged as YSE/w > MSE/w > CSE/w. YSE/e produced highest cytotoxicity with LC50 of $0.02 \pm 0.24 \mu \mathrm{g} / \mathrm{ml}$ and CSE/w was lowest toxic with LC50 of $3,134.45 \pm 0.80 \mu \mathrm{g} / \mathrm{ml}$. YSE/ w had LC50 of $257.11 \pm 0.29 \mu \mathrm{g} / \mathrm{ml}$ which was over $10^{3}$ less toxic than YSE/e. In addition, YSE/e caused $100 \%$ mortality of the brine shrimps within $12 \mathrm{~h}$. CSE/e cytotoxicity with LC50 of $72.30 \pm 0.75$ $\mu \mathrm{g} / \mathrm{ml}$ was 43 fold of CSE/w. MSE/e cytotoxicity with LC50 of $506.23 \pm 0.26 \mu \mathrm{g} / \mathrm{ml}$ was approximately 3 fold of MSE/w.

\section{Larvicidal Effects}

The efficacy of mintweed (MSE), yam bean (YSE) and celery (CSE) seed extracts on mortality of the $2^{\text {nd }}$ instar larvae of $A e$. aegypti determined by LC50 at $24 \mathrm{~h}$, was depend upon plant seeds, solvents, and concentrations. All ethanolic extracts produced higher mortality of the larvae than water extracts. The efficacy compared as YSE/e > YSE/w > MSE/e > CSE/e > MSE/w > CSE/w (Table 2). YSE/e, the most potent, had LC50 of $16.22 \pm$ $0.20 \mu \mathrm{g} / \mathrm{ml}$ and CSE/w, the least potent, had LC50 of $25,230.74 \pm$ $0.12 \mathrm{mg} / \mathrm{ml}$. YSE/e was 87 and 233 fold more potent in controlling of Ae. aegypti larvae than MSE/e and CSE/e respectively.

\section{Adulticidal Effects}

The Ae. aegypti adults were sprayed twice with various concentrations of the seed extracts of mintweed, yam bean and celery for $24 \mathrm{~h}$. The effects of the seed products were also depend upon plant seeds, solvents, and concentrations. The efficacy, deter- 
mined by LC50 values, compared as YSE/e > MSE/e > YSE/w > $\mathrm{CSE} / \mathrm{e}>\mathrm{MSE} / \mathrm{w}>\mathrm{CSE} / \mathrm{w}$ (Table 3). YSE/e, the most effective, showed LC50 value of $91.41 \pm 0.49 \mu \mathrm{g} / \mathrm{ml}$ and CSE/w, the least effective, showed LC50 value over $109 \mathrm{mg} / \mathrm{ml}$. YSE/e was 32 and 275 fold more effective in controlling of $A$ e. aegypti adults than MSE/e and CSE/e respectively.

\section{Effects of Extract Combinations}

The effects of seed extract combinations (pair wise; 1:1, v/v) on the $2^{\text {nd }}$ instar larvae and the adult mosquitoes were tested. The extract combinations enhanced the insecticidal activity against both $2^{\text {nd }}$ instar larvae and adult mosquitoes as compare to the mortality caused by individual extracts, except the combination of YSE/e and CSE/e (Table 4, 5 and 6) CSE/e reduced YSE/e individual effect. The combination of MSE/e and YSE/e exhibited the highest efficacy on the control of the $2^{\text {nd }}$ instar larvae with LC50 value of $11.79 \pm 0.15 \mu \mathrm{g} / \mathrm{ml}$ and on the adult mosquitoes with LC50 value of $23.82 \pm 0.20 \mu \mathrm{g} / \mathrm{ml}$. The combination of MSE/w and CSE/w showed the least insecticidal activity on both larvae and adult mosquitoes with LC50 of $5,086.76 \pm 0.10 \mu \mathrm{g} / \mathrm{ml}$ and $12,315.31 \pm 0.23 \mu \mathrm{g} / \mathrm{ml}$, respectively. It was noticed that YSE enhanced the activities of MSE and of CSE on both larvae and adults (Table 6). In addition, MSE enhanced only the activity of CSE with much less toxic magnitude than YSE did. The efficacy of the individual and the combination treatments of all extracts on Aedes aegypti larvae and adults are comparatively summarized in table 6.

\section{Discussion}

The biological control of Aedes aegypti, the important vector of the dengue hemorrhagic fever virus, in Thailand is very essential. Uses of natural products can avoid mosquitoes develop resistance to synthetic insecticides and safe to the environment and human beings as well. Plant products are possibly suitable alternatives and candidates as bio-insecticides for controlling of Ae. aegypti. Moreover, some plants are traditionally used for insect control in farms and are locally available. This study demonstrated the efficacy of three plant seed extracts which were mintweed Hyptis suaveolens (MSE), yam bean Pachyrhizus erosus (YSE) and celery Apium graveolens (CSE) in controlling of the $2^{\text {nd }}$ instar larvae and the adult Aedes aegypti. Since $H$. suaveolens contained $b$ - caryophyllene, 1,8-cineole, sabinene, b-selinene limonene, biclyclogermacrene, $b$-phellandrene, these phytochemicals could cause death to both larvae and adult mosquitoes [23-24]. There was a report that ethanolic extract of mintweed leaves could be used as larvicidal on Ae. aegypti larvae in Nigeria [11]. Petroleum ether extract of mintweed seeds was found against moth, Plutell xylostella [12]. However, mintweed extract at high dose, up to 500 $\mathrm{mg} / \mathrm{kg} /$ day for 6 months, did not produce any toxic effects in rats $[10,14]$. This could be certain that mintweed is safe to mammals, as confirmed by our investigation on brine shrimps. Celery seed extract (CSE) showed larvicidal and adulticidal activity against $A e$. aegypti to some certain extend. Possibly, its constituents of limonene, selinene, glucosides and flavonoid may not that toxic to mosquitoes [25-26]. However, there was a report that the essential oil of whole celery was potent as an adulticide to Ae. aegypti [6].

It is clearly, the ethanolic seed extract of yam bean, YSE/e, was most toxic to Ae. aegypti larvae and adults. YSE/e possibly contained high toxic products as it was reported that yam bean seeds comprised of rotenone and cyanogenic glycosides which were known poisonous to human beings and animals [16, 27]. Rotenone is now widely used as an insecticide in agriculture and home gardening, in particularly, controlling of aphids, thrips, lices, ticks, moths, beetles, spider mites, and mosquito larvae [28-29]. Rotenone caused death to insects by inhibited NADH oxidation in mitochondria leading to critically blocking respiration and nerve conduction [29]. Having yam bean seed extract in combinations with the other seed extracts highly enhanced the insecticidal efficacy on Ae. aegypti.

\section{Conclusion}

In conclusion, Yam bean seed extracted with ethanol was highly cytotoxic to a higher animal like brine shrimps. In our study was the first investigation in the biological control of Ae. aegypti by mintweed, yam bean and celery seed extracts. It is concluded that the seed extracts of these three plants were safe to be used as botanical insecticides in controlling of $A$ e. aegypti, the dengue hemorrhagic fever mosquito. The insecticidal efficacy of these three seed extracts is very broadly differences. Yam bean seeds are the most potent candidate as mosquito plant-based larvicide and adulticide. However, yam bean seed extracts must be used with caution, since it is highly toxic, unless combining them with other appropriate plant extracts to lessen their toxicity for animal and human safety. The information provided here will be useful for further study for applying the very toxic plant seeds in controlling other kinds of mosquitoes, the important vectors of many tropical diseases, and other insect pests.

\section{Acknowledgement}

This work was financially supported by Suranaree University of Technology and Mahasarakham University, Thailand. Aedes aegypti was a gift from Communicable Disease Control Centre, Zone 6, Ministry of Public Health, Khon Kaen, Thailand. We thank Dr. Hatsachai Boonjung for his kind reviewing of statistical analyses.

\section{References}

[1] Bureau of the vector-borne Diseases (2011) Department of Disease control, Ministry of Public Health, Thailand. http:// www/thaivbd.org/uploads/dengue/2553/52/w eeks.pdf.

[2] Wood A. (2010) Compendium of pesticide common names: Insecticides. http://www.alanwood.net/pesticides/index.html.

[3] Stenersen J. (2004) CRC Press; New York, U.K., 276.

[4] Mongkalangoon P., Grieco J.P., Achee N.L., Suwonkerd W., Chareonviriyaphap T. (2009) J. Vector Ecol., 34, 217-24.

[5] Lee H.L., Chen C.D., Masri S.M., Chiang Y.F., Chooi K.H., Benjamin S. (2008) Southeast Asian J. Trop Med Public Health, 39, 601-9.

[6] Chaiyasit D., Choochote W., Rattanachanpichai E., Chaithong U., Chaiwong P., Jitpakdi A., Tippawangkosol P., Riyong D. and Pitasawat B. (2006) Parasitol Res., 99, 715-721.

[7] Silva W.J., Dória G.A., Maia R.T., Nunes R.S., Carvalho G.A., Blank A.F., Alves P. B., Marçal R.M. and Cavalcanti S.C. (2008) Bioresour Technol., 99, 3251-3255.

[8] Gillij Y.G., Gleiser R.M., Zygadlo J.A. (2008) Bioresour Tech- 
nol., 99, 2507-15.

[9] Wulff R. (1987) Can J Bot., 65, 2501-6.

[10]Attawish A., Chivapat S., Chavalittumrong P., Phadungpat S., Bansiddhi J., Chaorai B. (2005) Songklanakarin J Sci Technol., 27, 1027-36.

[11]Amusan A.A.S., Idowu A.B., Arowolo F.S. (2005) Tanzan Health Res Bull, 7, 174-8.

[12]Keita S., Umoetok S.B.A., Smith J.G. (2006) Agric J., 1, 11-3.

[13]lloba B. N., Ekrakene T. (2006) J Biol Sci., 6, 626-30.

[14]Niwatananun K., Niwatananun W., Lertprasertsook L., Okonogi S. (2006) CMUJ, 5, 369-75.

[15]Morales-Arellano G.Y., Chagolla-López A., Paredes-López O., Barba R.A.P. (2001) J Agric Food Chem., 49, 1512-6.

[16]Hung Y.M., Hung S.Y., Olson K.R., Chou K.J., Lin S.L., Chung H.M., Tung C.N. and Chang J.C. (2007) Intern Med J., 37, 130 $-132$.

[17]Barrera-Necha L.L., Bautista-Banos S., Bravo-Luna L., Garcia -Suarez F.J., Alaez-Sololano D., Reyes-Chilpa R. (2004) Rev Mex Fitopatol., 2, 356-61.

[18]Boiling J. (2006) http://everygreenherb.com/fromAtoz/ celery.html.
[19]Choochote W., Tuetun B., Kanjanapothi Rattanachanpichai E., Chaithong U., Chaiwong P., Jitpakdi A., Tippawangkosol P., Riyong D. and Pitasawat B. (2004) J Vector Ecol., 29, 340366.

[20]Briski E., Stappen G., Bossier P., (2008) Aquaculture, 282, 19 $-25$.

[21]Abbot W.S. (1925) J Econ Entomol., 18. 265-267.

[22]Finny, D.J. (1971) Cambridge University Press, England, 333.

[23]Peerzada N. (1997) Mol J., 1, 165-168.

[24]Campos I.F.P., Heleno D.F., Suzana C.S. (2001) Phytochem., $57,733-6$

[25]Fehr D. (1979) Pharmazie, 34, 658-62.

[26]Garg S.K., Gupta S.R., Sharma N.D. (1980) Planta Med., 38 , 363-5.

[27]Narongchai P., Narongchai S., (2005) J Med Assoc Thai, 88, 984-7.

[28]Dayan F.E., Cantrell C.L., Duke S.O. (2009) Bioorg Med Chem., 17, 4022-34.

[29]Marrs T. C., Ballantyne B. (2004) John Wiley and Sons, West Sussex, England, 554.

Table-1 - Cytotoxic effects of seed extracts of mintweed (MSE), yam bean (YSE) and celery (CSE), determined by brine shrimp lethality assay (BSLA).

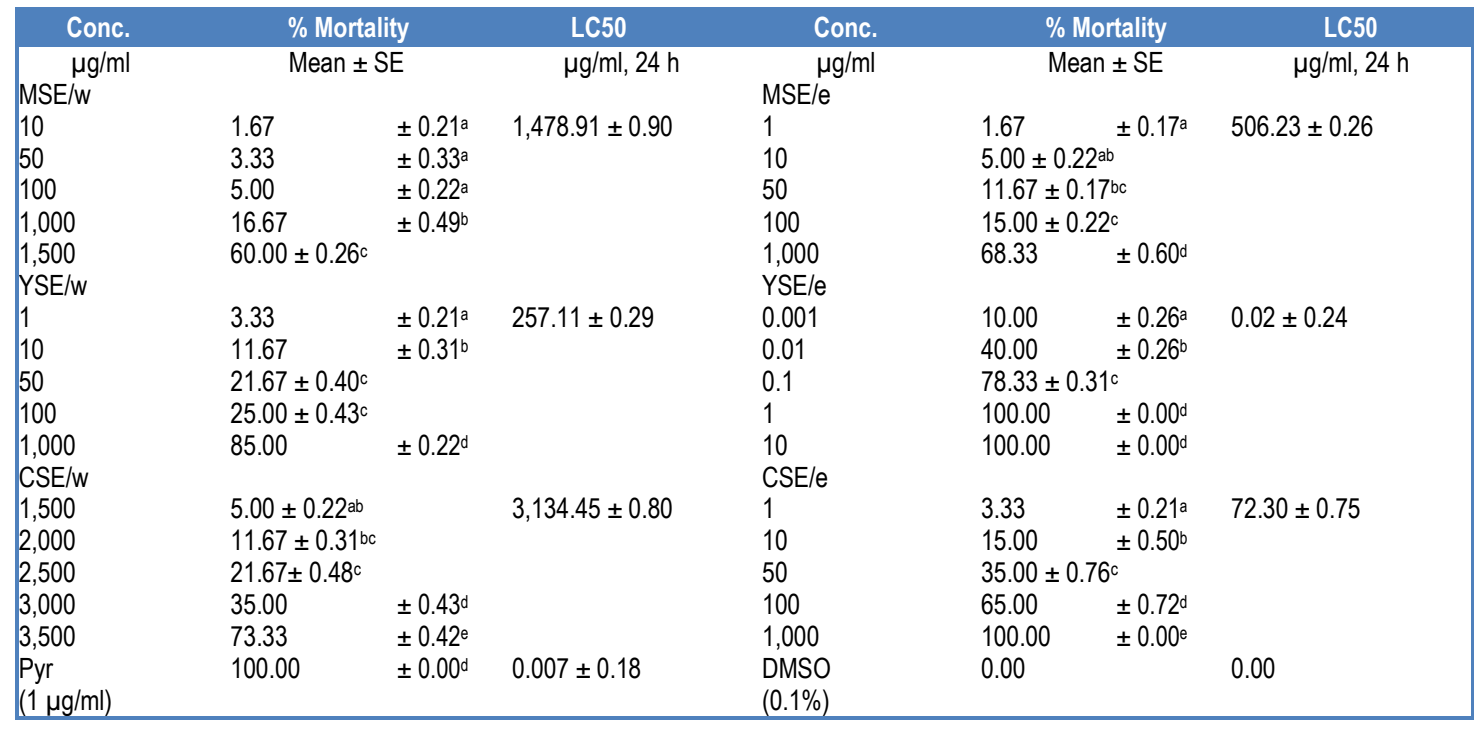

Each value is the mean \pm standard error, $n=6$. Numbers with different letters within the same column are significantly different $(P £ 0.05)$. Pyr is pyrethriod 
Yongkhamcha B. and Indrapichate K.

Table-2 - Effects of individual seed extracts of mintweed (MSE), yam bean (YSE) and celery (CSE) on the $2^{\text {nd }}$ instar larvae of Ae. Aegypti

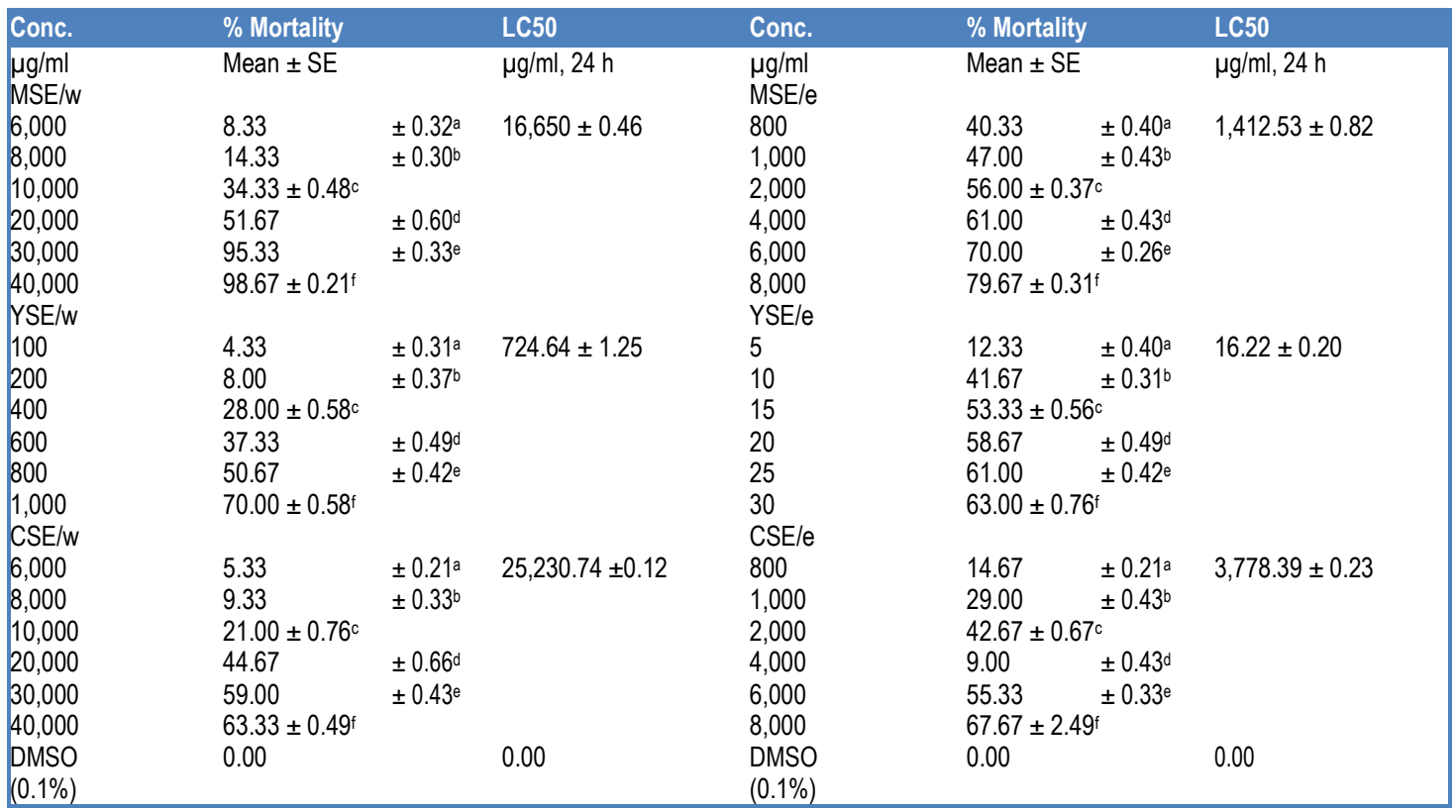

Each value is the mean \pm standard error, $n=6$. Numbers with different letters within the same column are significantly different $(P \leq 0.05)$. DMSO is dimethylsulfoxide.

Table-3 - Effects of individual seed extracts of mintweed (MSE), yam bean (YSE) and celery (CSE) on the adults of Ae. aegypti.

\begin{tabular}{|c|c|c|c|c|c|c|c|}
\hline Conc. & $\%$ Mortality & & LC50 & Conc. & \multicolumn{2}{|c|}{$\%$ Mortality } & LC50 \\
\hline $\begin{array}{l}\mu \mathrm{\mu g} / \mathrm{ml} \\
\mathrm{MSE} / \mathrm{w}\end{array}$ & Mean \pm SE & & $\mu \mathrm{g} / \mathrm{ml}, 24 \mathrm{~h}$ & $\begin{array}{l}\mu \mathrm{g} / \mathrm{ml} \\
\mathrm{MSE} / \mathrm{e}\end{array}$ & \multicolumn{2}{|c|}{ Mean \pm SE } & $\mu \mathrm{g} / \mathrm{ml}, 24 \mathrm{~h}$ \\
\hline 20,000 & 13.38 & $\pm 0.48^{a}$ & $75,046.45 \pm 0.12$ & 1,000 & 26.69 & $\pm 0.48^{a}$ & $2,952.70 \pm 0.11$ \\
\hline 40,000 & 20.74 & $\pm 0.62^{b}$ & & 2,000 & 41.22 & $\pm 1.00^{b}$ & \\
\hline 60,000 & $29.77 \pm 0.45^{c}$ & & & 4,000 & \multicolumn{2}{|c|}{$54.73 \pm 0.42^{c}$} & \\
\hline 80,000 & 54.85 & $\pm 0.43^{d}$ & & 6,000 & 58.45 & $\pm 0.43^{d}$ & \\
\hline 100,000 & 68.56 & $\pm 0.56^{\mathrm{e}}$ & & 8,000 & 77.70 & $\pm 0.52^{\mathrm{e}}$ & \\
\hline 200,000 & $84.62 \pm 0.49 f$ & & & & & & \\
\hline YSE/w & & & & YSE/e & & & \\
\hline 2,000 & 18.45 & $\pm 0.76^{a}$ & $9,600.51 \pm 0.25$ & 20 & 4.36 & $\pm 0.43^{a}$ & $91.41 \pm 0.49$ \\
\hline 4,000 & 28.52 & $\pm 0.43^{b}$ & & 40 & 10.74 & $\pm 0.33^{b}$ & \\
\hline 6,000 & $40.27 \pm 0.49 c$ & & & 60 & \multicolumn{2}{|c|}{$20.13 \pm 0.56^{c}$} & \\
\hline 8,000 & 47.31 & $\pm 0.47 \mathrm{~d}$ & & 80 & 46.64 & $\pm 0.89 \mathrm{~d}$ & \\
\hline 10,000 & 55.03 & $\pm 0.49 \mathrm{e}$ & & 100 & 57.38 & $\pm 0.48^{\mathrm{e}}$ & \\
\hline 20,000 & $61.74 \pm 0.26^{f}$ & & & & & & \\
\hline CSE/W & & & & $\mathrm{CSE} / \mathrm{e}$ & & & \\
\hline 20,000 & 4.02 & $\pm 0.31^{a}$ & $109,030.36 \pm 17$ & 10,000 & 15.88 & $\pm 0.40^{a}$ & $25,097.59 \pm 0.12$ \\
\hline 40,000 & 12.38 & $\pm 0.61^{\mathrm{b}}$ & & 20,000 & 47.64 & $\pm 0.91^{b}$ & \\
\hline 60,000 & $29.10 \pm 0.56 c$ & & & 40,000 & \multicolumn{2}{|c|}{$61.49 \pm 0.89 c$} & \\
\hline 80,000 & 44.15 & $\pm 0.60^{d}$ & & 60,000 & 68.92 & $\pm 0.42^{d}$ & \\
\hline 100,000 & 55.19 & $\pm 0.76 \mathrm{e}$ & & 80,000 & 97.97 & $\pm 0.52 \mathrm{e}$ & \\
\hline 200,000 & $63.55 \pm 0.31^{f}$ & & & & & & \\
\hline $\begin{array}{l}\text { DMSO } \\
(0.1 \%)\end{array}$ & 0.00 & & 0.00 & $\begin{array}{l}\text { DMSO } \\
(0.1 \%)\end{array}$ & 0.00 & & 0.00 \\
\hline
\end{tabular}

Each value is the mean \pm standard error, $n=6$. Numbers with different letters within the same column are significantly different $(P \leq$ 0.05). DMSO is dimethylsulfoxide 
Efficacy of Mintweed, Yam Bean and Celery Seed Extracts on Aedes aegypti L

Table-4 - Effects of the seed extract combinations (pair wise) of mintweed (MSE), yam bean (YSE) and celery (CSE) on the $2^{\text {nd }}$ instar larvae of Ae. aegypti.

\begin{tabular}{|c|c|c|c|c|c|}
\hline Combined & $\%$ Mortality & LC50 & Combined & $\%$ Mortality & LC50 \\
\hline $\begin{array}{l}\text { Extract } \\
\text { MSE/w + YSE/w }\end{array}$ & Mean \pm SE & $\mu \mathrm{g} / \mathrm{ml}, 24 \mathrm{~h}$ & $\begin{array}{l}\text { Extract } \\
\text { MSE/e + YSE/e }\end{array}$ & Mean \pm SE & $\mu \mathrm{g} / \mathrm{ml}, 24 \mathrm{~h}$ \\
\hline 400 & $49.00 \pm 0.43^{a}$ & $225.43 \pm 0.10$ & 5 & $25.67 \pm 0.31 a$ & $11.79 \pm 0.15$ \\
\hline 600 & $57.00 \pm 1.00^{b}$ & & 10 & $53.00 \pm 0.31^{b}$ & \\
\hline 800 & $67.67 \pm 0.48 c$ & & 15 & $70.33 \pm 0.56 c$ & \\
\hline 1,000 & $74.67 \pm 0.33^{d}$ & & 20 & $95.67 \pm 1.85 d$ & \\
\hline 2,000 & $80.00 \pm 0.48 \mathrm{e}$ & & 30 & $97.67 \pm 0.40 \mathrm{e}$ & \\
\hline CSE/w + MSE/w & & & CSE/e + MSE/e & & \\
\hline 2,000 & $36.00 \pm 0.45^{a}$ & $5,086.76 \pm 0.10$ & 40 & $21.67 \pm 0.52^{a}$ & $121.66 \pm 0.10$ \\
\hline 4,000 & $43.33 \pm 0.33^{b}$ & & 60 & $41.00 \pm 0.43^{b}$ & \\
\hline 6,000 & $51.33 \pm 0.67^{c}$ & & 80 & $50.00 \pm 0.49 c$ & \\
\hline 8,000 & $56.00 \pm 0.45^{d}$ & & 100 & $68.00 \pm 0.84^{d}$ & \\
\hline 10,000 & $60.33 \pm 0.40 \mathrm{e}$ & & 200 & $77.33 \pm 0.56 \mathrm{e}$ & \\
\hline YSE/w + CSE/w & & & YSE/e + CSE/e & & \\
\hline 200 & $24.00 \pm 0.52^{a}$ & $930.65 \pm 0.10$ & 40 & $21.67 \pm 0.91 \mathrm{a}$ & $82.04 \pm 0.10$ \\
\hline 400 & $31.67 \pm 0.31 b$ & & 60 & $41.00 \pm 0.43^{b}$ & \\
\hline 600 & $36.00 \pm 0.37 c$ & & 80 & $50.00 \pm 0.37 c$ & \\
\hline 800 & $44.00 \pm 0.37^{d}$ & & 100 & $68.00 \pm 0.37^{d}$ & \\
\hline 1,000 & $55.33 \pm 0.49 e$ & & 200 & $77.33 \pm 0.42^{\mathrm{e}}$ & \\
\hline $\begin{array}{l}\text { DMSO } \\
(0.1 \%)\end{array}$ & 0.00 & 0.00 & $\begin{array}{l}\text { DMSO } \\
(0.1 \%)\end{array}$ & 0.00 & 0.00 \\
\hline
\end{tabular}

Each value is the mean \pm standard error, $n=6$. Numbers with different letters within the same column are significantly different (P $£$ 0.05). DMSO is dimethylsulfoxide. 